By invitation of the same committee there were two special sessions of selected twenty-minute papers, each of which met both morning and afternoon. Professor Donald J. Lewis of the University of Michigan arranged one such session on the subject of Number Theory; the speakers were Peter E. Blanksby, Harold G. Diamond, Patrick X. Gallagher, William J. Ellison, Takashi Ono, Carl Riehm, Wolfgang M. Schmidt, J. Roderick Smart, Harold M. Stark, and George Whaples. The other special session was arranged by Professor James B. Serrin of the University of Minnesota on the subject of Partial Differential Equations; the speakers were Felix E. Browder, Todd Dupont, Jr., Eugene B. Fabes, Robert Finn, Keith Miller, Johannes C. C. Nitsche, Ralph S. Phillips, James B. Serrin, Joel A. Smoller, W. Gilberg Strang, and François Treves.

There were four sessions for twenty-seven contributed ten-minute papers. Professors George E. Hay, James M. Kister, Jack E. McLaughlin, and Lee A. Rubel were the session chairmen.

On Friday, November 28, 1969, the day before the meeting itself, the University of Michigan sponsored a Symposium on Function Algebras and Rational Approximation, with the support of the $\mathrm{Na}$ tional Science Foundation. The speakers were Herbert J. Alexander, Andrew Browder, Brian Cole, Theodore W. Gamelin, John B. Garnett, Donald E. Sarason, and John Wermer. On Sunday and Monday, November 30 and December 1, 1969, the two days following the meeting of the American Mathematical Society, the Society for Natural Philosophy held a meeting on the subject of Optimal Control and the Calculus of Variations. The speakers were Lamberto Cesari, Wendell H. Fleming, Elmer G. Gilbert, Henry G. Hermes, Lucien W. Neustadt, and Jack Warga.

Urbana, Illinois

Paul T. Bateman Associate Secretary

\title{
STEELE PRIZES FOR EXPOSITORY PAPERS
}

Through a bequest to the Society by Leroy P. Steele, a prize has been established in honor of George D. Birkhoff, William Fogg Osgood, and William Caspar Graustein for outstanding published mathematical research. One or more prizes will be awarded each year, at the Summer Meeting, beginning in 1970. Most favorable consideration will be given to papers distinguished for their exposition and covering broad areas of mathematics. It is expected that each prize will be in the amount of $\$ 1,000$ or more. 